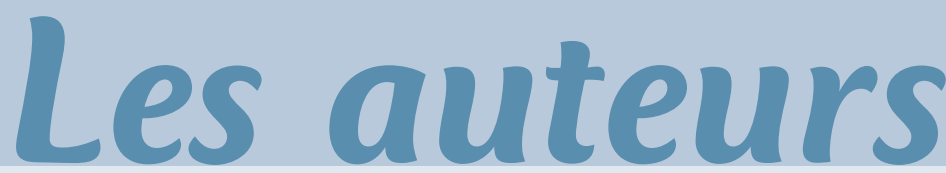

David Garon est docteur en pharmacie diplômé de la Faculté de Pharmacie de Grenoble et Professeur de botanique, mycologie et biotechnologies à l'UFR des Sciences Pharmaceutiques de l'Université de Caen. Il enseigne la biodiversité, les sciences végétales et fongiques. Ses travaux de recherche en santé-environnement ont d'abord porté sur la biodépollution de sols contaminés puis il s'est orienté vers l'étude de l'écologie, des moisissures, de leur diversité et de la toxicité de leurs métabolites secondaires.

Jean-Christophe Guéguen est docteur en pharmacie, diplômé de la Faculté de Pharmacie Paris $\vee$ René Descartes et pharmacien industriel. Il a travaillé sur la recherche de substances naturelles (microbiennes, végétales et animales) d'intérêt pharmacologique. Il est conférencier dans plusieurs universités où il enseigne la chimie des substances naturelles et la biodiversité. Il est auteur, co-auteur et illustrateur de plusieurs ouvrages sur la botanique, les plantes médicinales et les plantes à parfum.

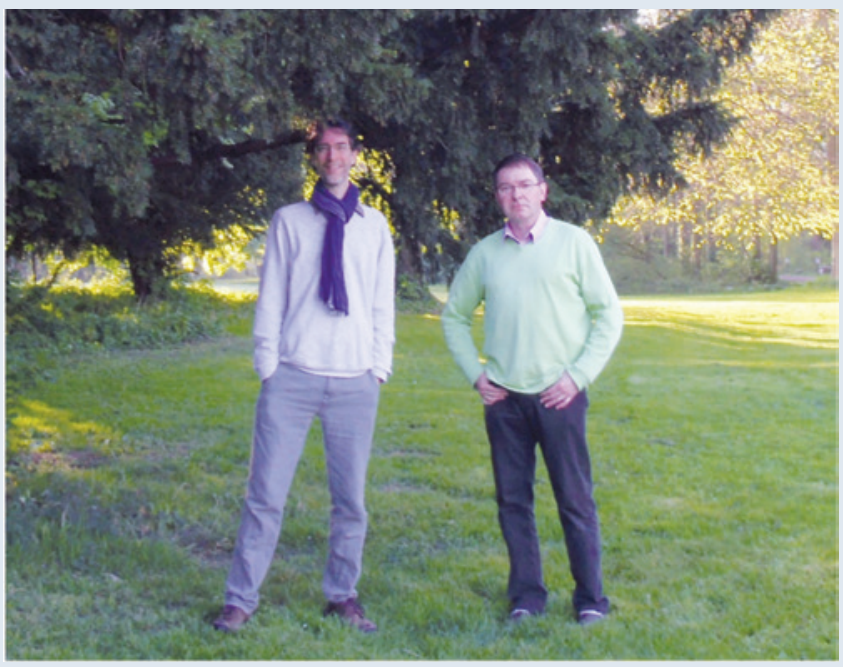

À droite : Jean-Christophe Guéguen.

À gauche : David Garon. 
Cet ouvrage est respectueusement dédié à la mémoire de Françoise Seigle-Murandi, Professeure de botanique et mycologie à I'UFR de Pharmacie de Grenoble. Passionnée par le monde fongique, elle fut à l'origine de nombreux travaux sur les micromycètes.

\section{David Garon}

À ma grand-mère Adrienne qui a partagé avec moi ses coins à champignons dans les bois du Chavanon, en Haute-Corrèze. En souvenir de ces soirées passées devant le cantou et des histoires qu'elle me racontait à la veillée.

\section{Jean-Christophe Guéguen}

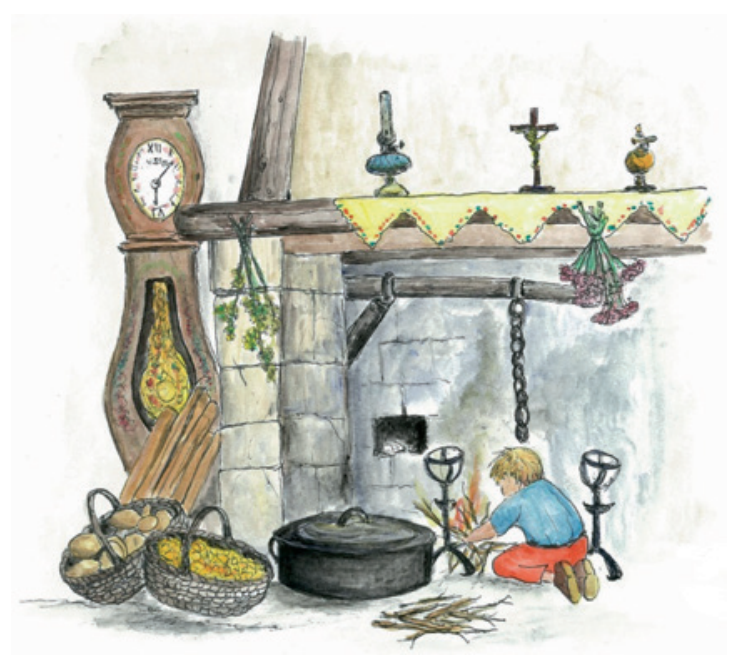

